band the width of which increases with concentration of impurity. The mid-point of this band will overlap the conduction band, they estimate, at a concentration of $10^{18}$ atoms/c.c. Above this concentration the material will continue to be conducting down to zero temperature, analogously to the results reported by Rollin and Petford for InSb. The lowest unfilled level available for optical transitions will increase with rising donor impurity content; on the other hand, the addition of electron acceptor impurities should empty the upper levels and therefore extend the limit of optical transitions to longer wave-lengths. This they have observed experimentally.

The compound CdTe was dealt with in a paper by Dr. F. A. Kröger and D. de Nobel (Philips Research Laboratories, Eindhoven) in which they described the preparation and properties of single crystals. Both $n$ - and $p$-type crystals can be obtained by adjusting the stoichiometric balance, which can be done by heating the crystal in a suitable pressure of cadmium vapour. Thermoelectric measurements gave values for the effective masses of electrons and holes of 0.37 and 0.14 times the free mass, respectively. The corresponding mobilities were 600 and $50 \mathrm{~cm}^{2} / \mathrm{V}$. sec. Estimates of the energy gap gave two different possible results : the value could be either 0.37 or $0 \cdot 2 \mathrm{eV}$. W. S. Lawson (Radar Research Establishment, Malvern) similarly dealt with the compound $\mathrm{Mg}_{2} \mathrm{Sn}$, of which he has grown crystals of high purity. The value of the energy gap is $0.34 \mathrm{eV}$. from measurements of Hall constant, and the same result can be derived from variation of the conductivity with temperature if plausible assiumptions are made about the dependence of mobility on temperature. The mobilities at room temperature are 220 for electrons and $260 \mathrm{~cm} \cdot{ }^{2} / \mathrm{V}$. sec. for holes.

Drs. J. van den Boomgaard, F. A. Kröger and H. J. Vink (Philips Research Laboratories, Eindhoven) gave a short paper on a technique of zonerefining a compound, such as $\mathrm{PbS}$, in which one of the components, here sulphur, is volatile. The compound is sealed in a silica tube, one ond of which is extended and connected to a sealed reservoir of the volatile compound. During the refining the auxiliary reservoir is kept at a temperature sufficient to give the desired vapour pressure of the volatile constituent, the remainder of the tube being kept at a rather higher temperature.

Finally, there were two papers dealing with applications. H. J. Goldsmid (General Electric Co., Ltd., Wembley) discussed the factors controlling the efficiency of a thermoelectric generator. The Fermi level (chemical potential) should lie near the edge of the appropriate band, and the mobility $(\mu)$ should be large, but not due to the occurrence of a small effective mass $\left(m^{*}\right)$; the controlling factor is $\mu\left(m^{*}\right)^{3 / 2}$, which should be large. The lattice component of thermal conductivity should be small. These requirements are most likely to be met when the mean atomic weight is large. For example, bismuth telluride (mean atomic weight 160) is particularly efficient. Using a junction of $n$ - and $p$-type material, an appreciable Peltier cooling has been obtained (40 deg. C. refrigeration). The abnormally high electron mobility of InSb has led to a number of new applications, discussed in a paper by I. M. Ross and Dr. E. W. Saker (Services Electronics Research Laboratory, Baldock). The power available from the Hall effect is proportional to the square of the mobility, which gives InSb, with its electron mobility of $60,000 \mathrm{~cm} .{ }^{2} / \mathrm{V}$. sec., a factor of $\sim 300$ improvement over germanium. Applications based on this feature include sensitive magnetometers, an electric compass, and a new type of power amplifier in which the input signal modulates the magnetic field in a thin crystal of the material. A new transducer principle is also possible in which the displacement to be observed causes the crystal to move in a steeply varying magnetic field. Using InSb as a resistance 'gyrator', a backward attenuation of $\sim 80 \mathrm{db}$. can be obtained for a forward loss of only $7 \cdot 5 \mathrm{db}$.

I. M. Ross

\section{LIBERAL VALUES IN FURTHER EDUCATION AND TRAINING}

$\mathrm{U}$ NDER the title "Liberal Education in a Technical Age", the National Institute of Adult Education has published the report of a survey of the relationship of vocational and non-vocational further education and training conducted by a Committee set up early in 1953 by the Institute jointly with the Associations of Technical Institutions and of Principals of Technical Institutions, with Sir Robert Wood as chairman and Dr. P. F. R. Venables as vice-chairman. Regarding a hberal education as one which includes a training in the use of language, in the handling of ideas, in recognizing relationships, and in establishing values as touchstones for questions of taste and morals, the Committee concerned itself with the fundamental questions of the extent to which these values are affected if a study is undertaken from motives connected with personal advancement, and the extent to which they are excluded from certain studies because of their subject-matter. Attention was concentrated on the work of the technical institutions and colleges of art, correspondence courses, adult education and residential colleges, and on the role of the professional and examining bodies. Following three chapters dealing with the background of the inquiry, which include statistics relating to institutions and students, there are chapters on each of these aspects, as well as one on teachers and students in technical institutions.

Broadly, the Committee addressed itself to three questions : the extent to which technical institutions recognize any responsibility for giving their students something more than vocational instruction; if such responsibility is recognized, whether the conditions under which further education is carried on permit of anything beyond the essential technical instruction; and whether, to maintain a due balance between vocational and general education, we should look to changes in the curricula of technical institutions, or to the phasing of the whole educational process. The Committee believes that at no period in the educational process should the values commonly associated with a general education be dropped because of the intense pressure of vocational preparation, and it declined to support any suggestion that students entering technical institutions can properly embark upon a period of narrow and specialist education to the neglect of other studies. This more generous view of vocational education, it found, is held by many principals and teachers in technical institutions in spite of the gap existing between what is regarded as desirable and what is, 
in practice, achieved. It emphasizes that the problem can only be resolved by the pressure of public opinion and, in particular, when industry, commerce and public administration at all levels of responsibility, from higher management to supervision, share the serious concern voiced by a minority, to the extent of a readiness to extend day-time release and insist on including non-vocational as well as vocational studies.

The sharpest criticism made by the Committee is of some of the professional and examining bodies, the papers and syllabuses of which are framed to encourage the memorizing of facts rather than the discussion of underlying principles. This practice is largely responsible for the narrowness of certain technical studies, and the Committee believes that these bodies should be invited to re-assess the purpose and nature of their examinations. The Committee also comments on the unsatisfactory physical environment in which the work of technical institutions is often performed. It welcomes the recent relaxation of the utilitarian attitude of the Ministry of Education towards vocational education and hopes that local education authorities and governing bodies will now press forward with the improvement of physical conditions, including the equipment and maintenance of libraries, an increased supply of technical and non-technical books and periodicals, and the provision of adequate refectories, recreation and common rooms. The Committee believes that all education must aim at increasing human sympathy and understanding, sharpening æsthetic appreciation and giving a better command of language, and to this end it recommends that human relations in industry and commerce should be more widely studied and the æsthetic appreciation of design appropriately emphasized. It further recommends that, in technical and professional examinations at all levels, some regard should be had to the qualities derived from liberal studies, and directs attention to the value of short periods of residential education and of foreign travel. It suggests that the links between technical institutions and the responsible bodies in adult education could be strengthened with advantage to both and that the experiments being made in the university world on the reconciliation of vocational and liberal education could be profitably studied in relevance to other forms of higher education.

\section{INTAKE OF NUTRIENTS BY SUGAR-BEET}

\footnotetext{
A

STUDY of the interactions of nitrogen, phosphorus and potassium, supplied in leaf sprays or as fertilizer added to the soil, has been reported on by G. N. Thorne (J. Exp. Bot., 6, 16, 20 ; 1955). Among findings of special interest are the following.

When sugar-beet plants grown in pots were sprayed daily with nutrient solutions supplying nitrogen, phosphorus and potassium separately or in all combinations, with precautions to prevent spray falling on the soil in which the plants were grown, all three nutrients were absorbed through the leaves. In one experiment nitrogen and potassium, and in another only nitrogen, caused increases in plant dry weight and leaf-area. Swedes absorbed phosphorus from leaf sprays and from fertilizer applied to the
}

soil, but only the fertilizer caused an incroase in dry weight.

Absorption of any of the nutrients tested from a spray containing more than one nutrient was unaffected by the presence of others in the spray; but spraying with nitrogen-containing solutions increased the absorption of phosphorus and potassium from the soil, and potassium in sprays increased the uptake of phosphorus from the soil. Nitrogenous fertilizer applied to the soil increased the leaf-area of sugar-beet plants, and hence it also increased the amounts of nitrogen, phosphorus and potassium deposited on the leaves when they were sprayed with solutions of these nutrients, and the amounts absorbed from the spray into the plants. Phosphatic fertilizer had no effect on uptalie from leaf sprays. Potassic fertilizer did not affect leaf-area or the estimated volume of spray solution retained on the leaves; but it appeared to reduce uptake of potassium from the spray. Dry woight per plant was increased by all three nutrients in fertilizer, and sugar yield of the roots was increased by nitrogen and potassium in fertilizer, and by nitrogen in spray. Application of a nutrient in leaf spray reduced the responses in dry weight and sugar yield to the same nutrient applied in fertilizer to the soil.

\section{JUTE PRODUCTION AND RESEARCH}

$\mathrm{R}$ EADERS interested in the problems of jute production in India will find a comprehensive account of relevant matters in the annual report of the Indian Central Jute Committee (for 1953-54, pp. 1-300; Calcutta) and in the annual report of the Jute Agricultural Research Institute (1953-54, pp. 1-145; 1955 , Calcutta).

The primary object of this central authority is to deal with research on all aspects of jute from field to factory. The reports accordingly have sections devoted to the relevant agricultural, technological and economic aspects. At the Jute Agricultural Research Institute the programme includes jute breeding and eytogenetics, special problems of anatomy, the agronomy of jute and of crops yielding substitute fibres, and related physiological, microbiological and entomological problems. On the technological side, in addition to the normal testing, development and processing work, more fundamental researches on chemical and physical aspects have also been undertaken.

In investigations of the chemistry of the hemicelluloses of jute and other fibres it has been found that these are generally similar. Further evidence has been obtained supporting a hypothesis put forward earlier of a chemical combination between the carboxyl group of the hemicellulose and the hydroxyl group of the lignin in jute. On the physical side, the torsional rigidity of jute, ramie and sisal has been measured. It has been ascertained that heavier filaments have generally lower values for rigidity modulus and that porosity appears to be related inversely to rigidity. The elastic properties of jute filaments from plants at different stages of growth, and the effects of chemical and physical treatments on the hardness modulus of jute fibre, have been investigated. Some progress in X-ray investigations of jute fibre is also reported : here the principal aim was to ascertain the size of the micelles in fibres of different quality ratios. 